\title{
EL MANÍ DE LLULLAILLACO
}

\author{
ANTONIO KRAPOVICKAS ${ }^{1} \&$ RICARDO O. VANNI ${ }^{1}$
}

Summary: Krapovickas, A. \& R. O. Vanni. 2009. The peanut from Llullaillaco. Bonplandia 18(1): 51-55. ISSN: 0524-0476.

The archeological peanut found at $6715 \mathrm{~m}$ on the Cerro Llullaillaco (24\% $45^{\prime} \mathrm{S}-68^{\circ} 30^{\prime} \mathrm{W}$ ) is identified as Arachis hypogaea L. var. hypogaea, race 'Guaycurú' from de lowlands of South America.

Key words: archeology, peanut, Arachis hypogaea

Resumen: Krapovickas, A. \& R. O. Vanni. 2009. El maní de Llullaillaco. Bonplandia 18(1): 5155. ISSN: 0524-0476.

El maní arqueológico hallado a $6715 \mathrm{~m}$ de altura en el cerro Llullaillaco (244ㄴ'S-6830'W) se identifica como Arachis hypogaea L. var. hypogaea, raza 'Guaycurú', cultivo de las tierras bajas de Sudamérica.

Palabras clave: arqueología, maní, Arachis hypogaea

En la cima del cerro Llullaillaco (24\% $45^{\prime}$ 'S$\left.68^{\circ} 30^{\prime} \mathrm{W}\right)$, en la provincia de Salta, en el límite con Chile, a $6715 \mathrm{~m}$ de altura se encontraron tres niños momificados, cuyos cadáveres estaban acompañados de ofrendas y de alimentos. Entre éstos figuran frutos de maní en muy buen estado de conservación. Por los atuendos y las ofrendas los niños se identifican con la cultura Inca que se estableció en el lugar poco antes de la llegada de los españoles, entre 1471 y 1532 (Reinhard, 1999).

El maní de Llullaillaco (Fig. 1) se puede identificar, es idéntico al maní 'guaycurú' o 'guanaco' (Arachis hypogaea var. hypogaea), que en el presente se cultiva en las partes bajas de Salta y de Bolivia y que se extiende hasta el nordeste de Brasil (Figs. 2, 3, tabla 1). De este maní se conocen dos clases que se diferencian por el color del grano: pálido y colorado, ambas se cultivan actualmente en Corrientes. Usualmente los frutos tienen 2 granos pero no es infrecuente la presencia de 3 granos en un fruto.

Este es el maní que Marcgrave (1648) en-

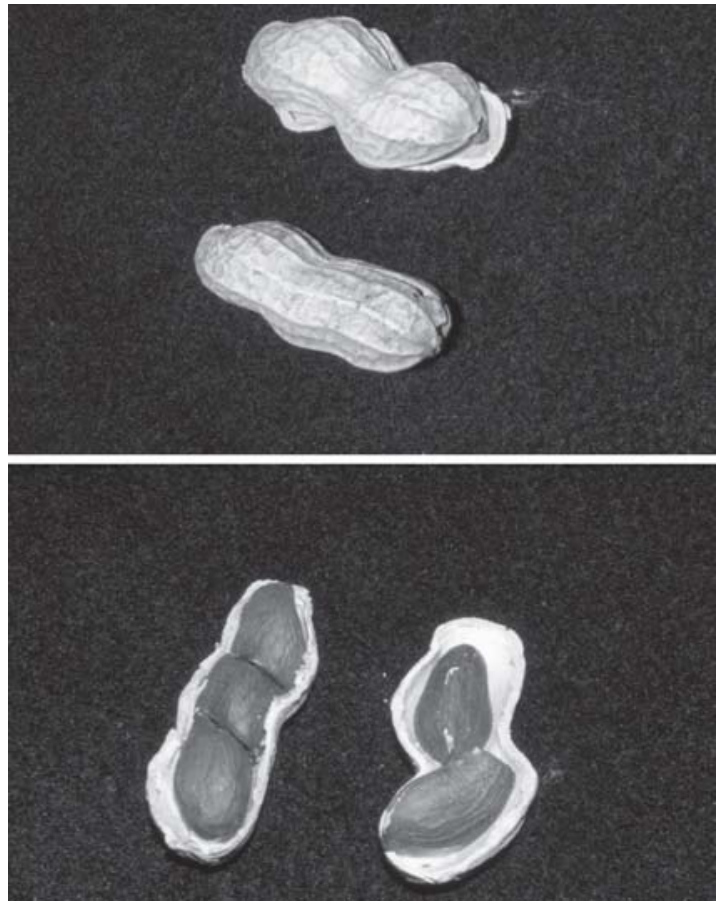

Fig. 1. Maníes con semillas hallados en el cerro Llullaillaco a $6715 \mathrm{~m}$ de altura.

${ }^{1}$ Instituto de Botánica del Nordeste, Casilla de Correo 209, 3400 Corrientes, Argentina. 

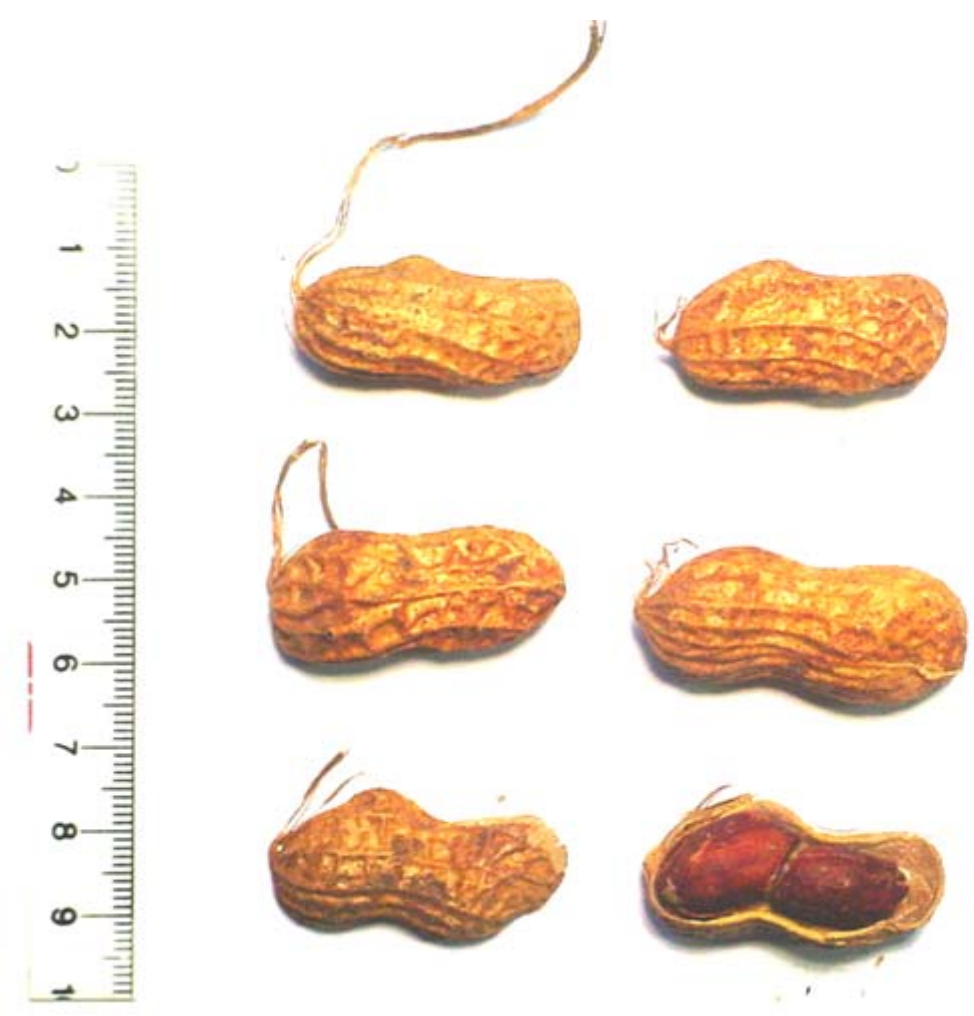

Fig. 2. Maní ‘guanaco’ o ‘guaicurù’ actual.

contró en el nordeste de Brasil durante la ocupación holandesa (Fig. 4).

También es el maní que ilustraron (Figs. 5-

Tabla 1. Límite altitudinal del maní 'guaicurú'.

\begin{tabular}{llll}
\hline Bolivia & & m & \\
\hline Pando & Cobija & 260 & W825 \\
La Paz & San Pedro & 800 & BZCJ 386 \\
& Caranavi & 600 & BZCJ 391 \\
& & & BZCJ 392 \\
Tarija & San Telmo & 500 & KFM 1472 \\
& & & KFM 1474 \\
& Bermejo & 400 & GK... 8 \\
& & & GK... 10 \\
\hline
\end{tabular}

Argentina

Salta $\quad$ Apolinario Saravia 358
7) los jesuitas de las misiones guaraníes: Montenegro (1710), Paucke (1749-1767) y Sánchez Labrador (1772) y que son reproducidas por Furlong (1948).

Es el maní "tipo 12" que Clos (1939, fig. 1: 11 y 12) menciona para Picada Finlandesa (Misiones), "maní indio" para Coronel Moldes (Salta), "maní perla" (Figs. 11 y 12) para Riachuelo (Corrientes) y "maní guanaco" para Perico (Jujuy).

La presencia de estos maníes en la cima de los Andes es una prueba irrefutable de las conexiones entre los indígenas de las llanuras orientales con los de las altas montañas o con los de la Puna.

Sobre estas conexiones, hay otra prueba como es el hallazgo de semillas del "urucú" (Bixa orellana), cultivo prehispánico de las llanuras tropicales encontrado en Catamarca a $2700 \mathrm{~m}$ de altura (Fig. 8) que datan del período temprano anterior a 600 A.D. (González \& Pérez, 1968).

En el NW argentino se encontraron otros maníes arqueológicos pero estos pertenecen a 


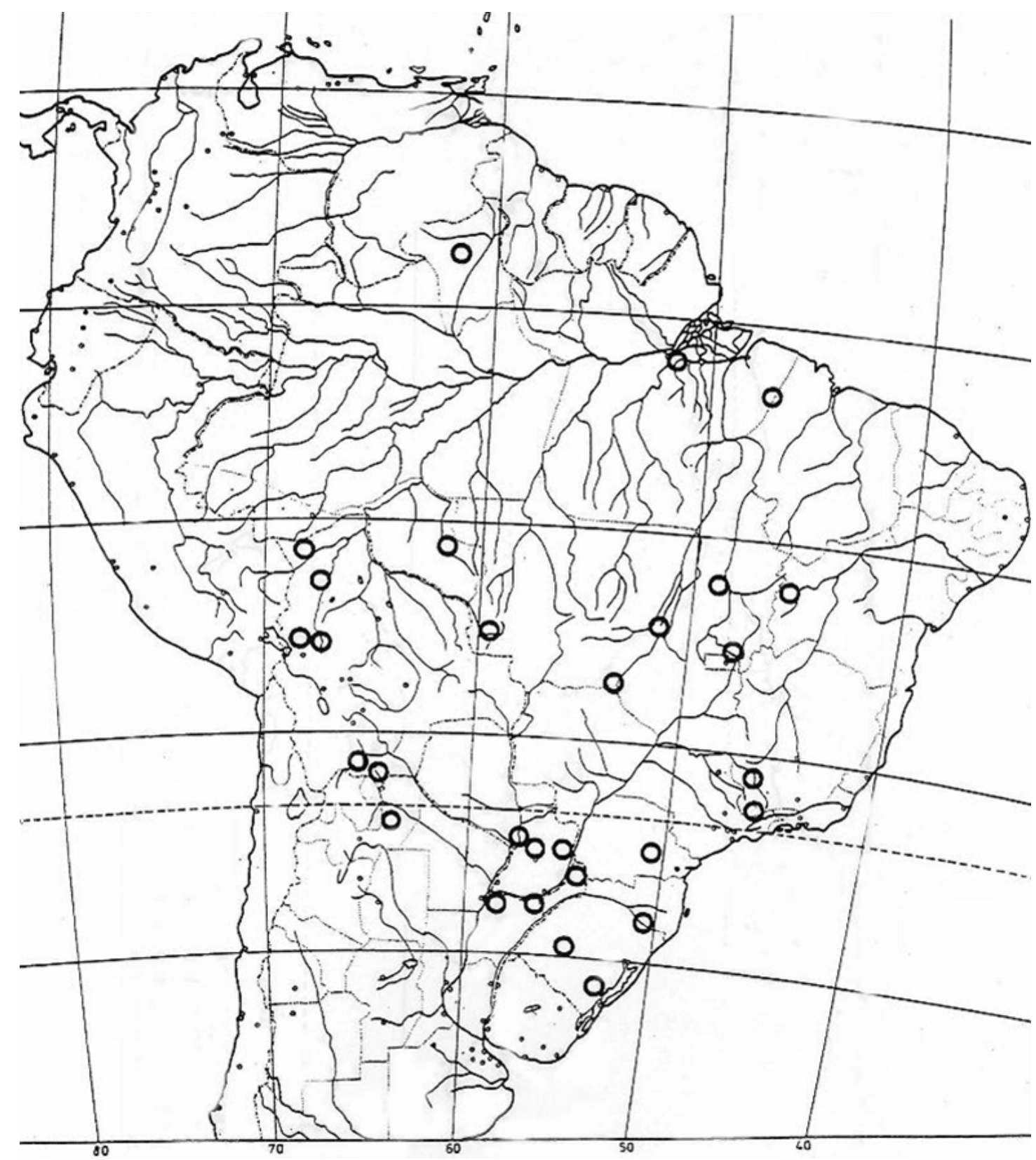

Fig. 3. Mapa de distribución actual del maní "guaicurú".

la variedad hirsuta, con estrechas vinculaciones con la costa del océano Pacífico.

\section{Agradecimientos}

de Salta las fotografías de los maníes de Llullaillaco (Figs. 1 y 2). 


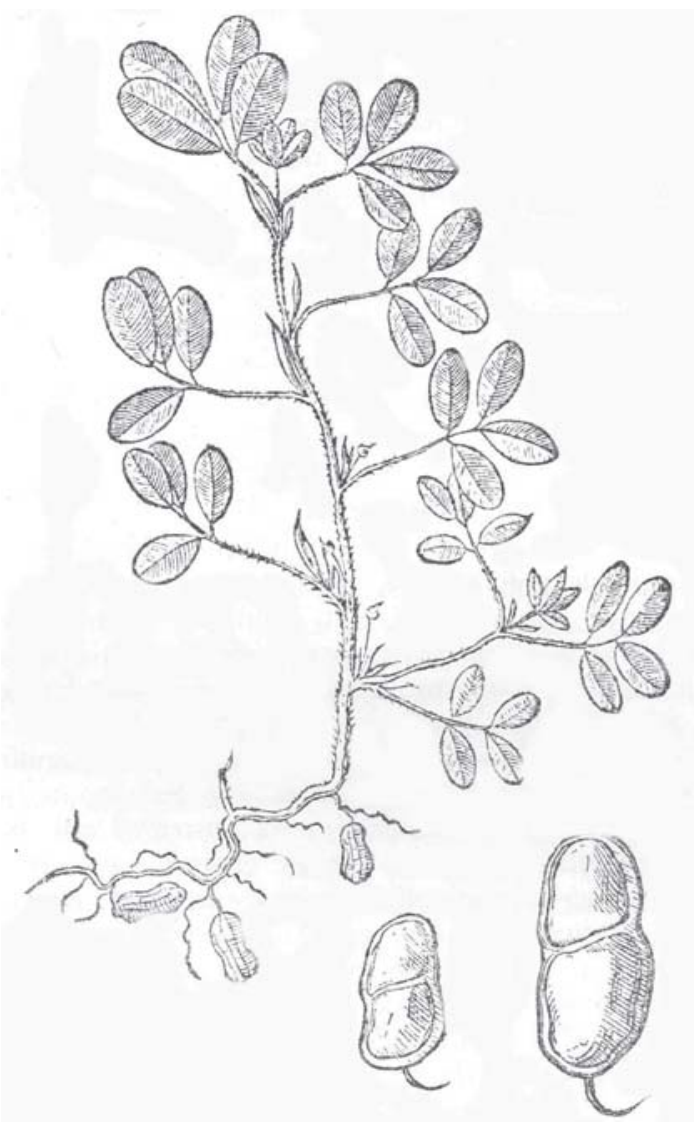

Fig. 4. Primera ilustración de Arachis hypogaea por Marcgrave, 1648.

\section{Maniatns Befaciayole}

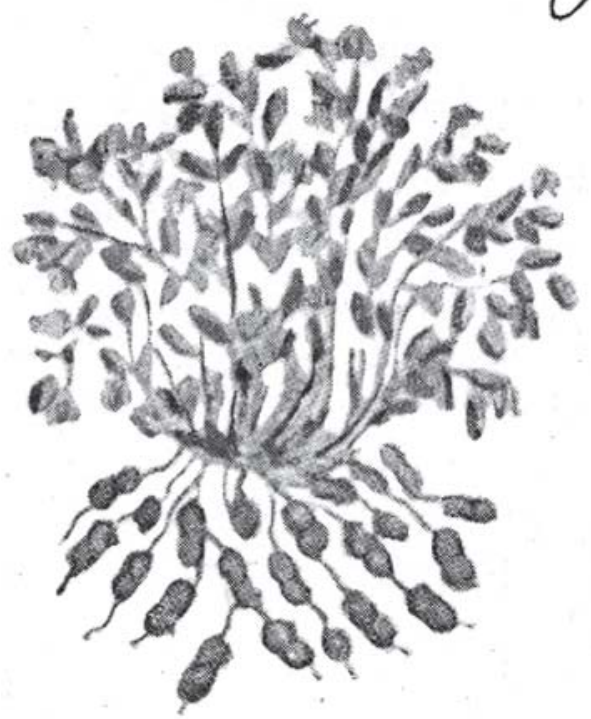

Fig. 6. El maní del padre Florián Paucke, 1749-1767.

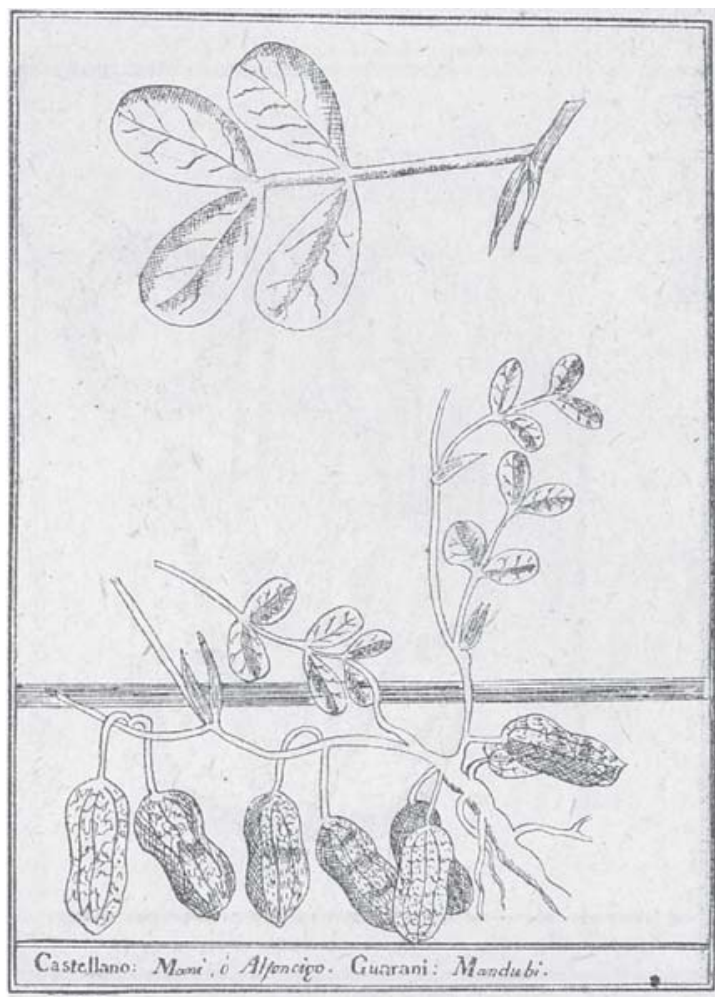

Fig. 5. El maní del padre Pedro Montenegro, 1710.

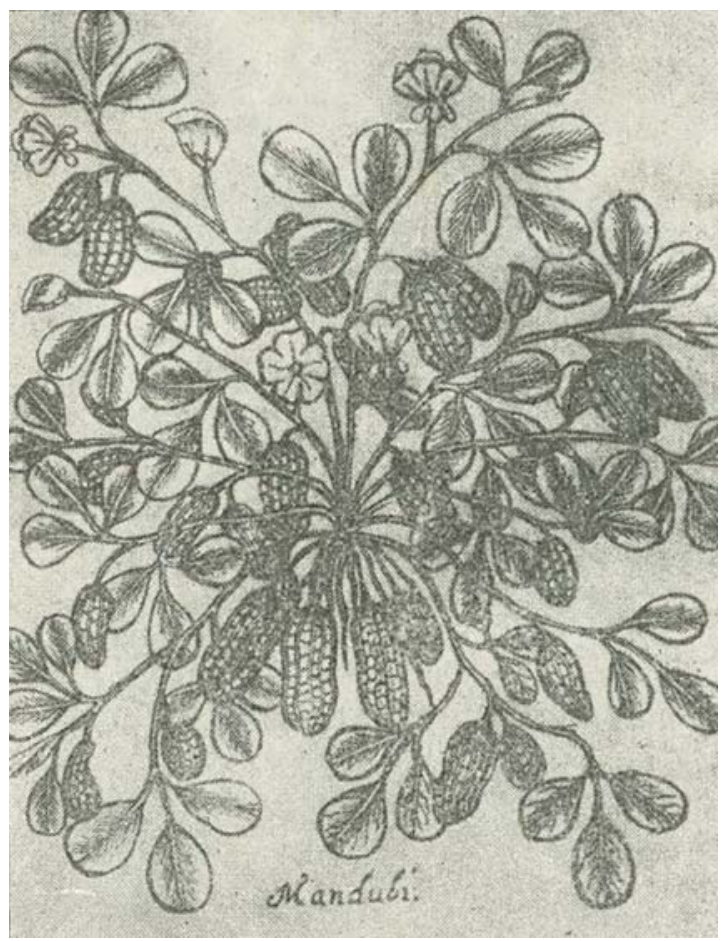

Fig. 7. El maní del padre José Sánchez Labrador, 1772. 

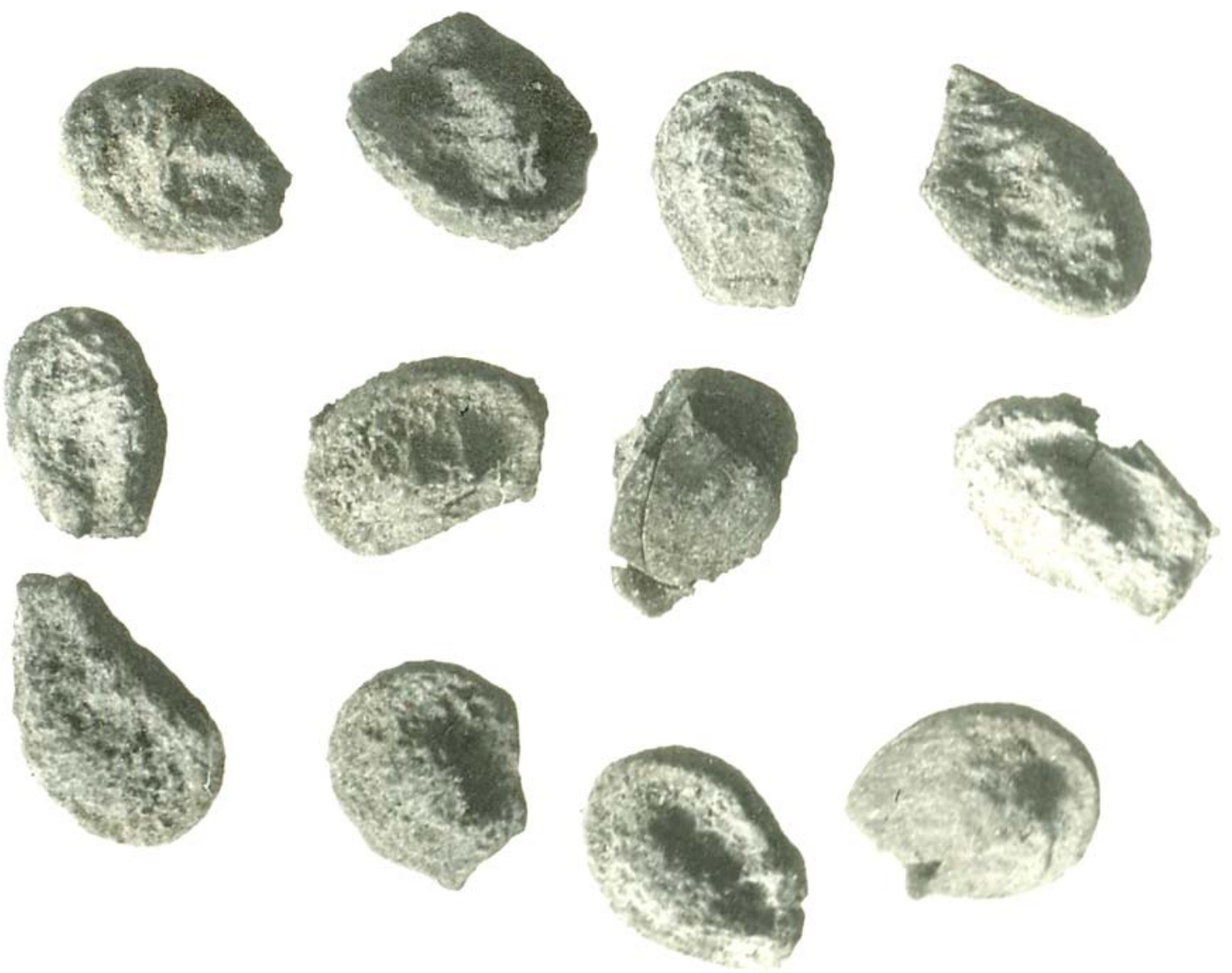

Fig. 8. Semillas arqueológicas de "urucú" (Bixa orellana). Tomado de González \& Pérez (1968).

hypogaea") cultivados en la Argentina y su distribución geográfica. Physis 18: 317-329.

FURLONG, G. 1948. Naturalistas argentinos durante la dominación hispánica. Huarpes, Buenos Aires, 431 pp.

GONZALEZ, A. R. \& J. A. PEREZ. 1968. Una nota sobre etnobotánica del N. O. argentino. Actas y Memorias, XXXVII Congreso Internacional de Americanistas, Argentina, 1966. Vol. II: 209-228 y 4 láminas.

MARCGRAVE, G. 1648. Historiae rerum naturalium Brasiliae. Tradução de Mons. Dr. José Procopio de Magalhaes. Edição do Museu Paulista. São Paulo 1942. MONTENEGRO S. J., H. P. 1945. Materia médica mi- sionera. Buenos Aires, Imprenta de la Biblioteca Nacional.

PAUCKE S.J., F. 1749-1767. Hacia allá y para acá (Una estadía entre los indios mocobíes). Traducción castellana por E. Wernicke. 3 tomos. Tucumán - Buenos Aires. 1942-1944.

REINHARD, J. A. 1999. A 6700 metros niños incas sacrificados quedaron congelados en el tiempo. National Geographic 5(5): 36-55.

SANCHEZ LABRADOR s.j., P. J. 1771-1776. La medicina en el "Paraguay Natural". Exposición comentada del texto original por el Dr. Aníbal Ruiz Moreno, Tucumán, 1948.

Original recibido el 27 de julio de 2009; aceptado el 14 de agosto de 2009. 
BONPLANDIA 18(1). 2009 